Pacific Journal of Mathematics

PLANE CURVES AND REMOVABLE SETS 


\title{
PLANE CURVES AND REMOVABLE SETS
}

\author{
R. KAUFMAN
}

Various function spaces defined outside a curve $\Gamma$ are introduced, along with their subspaces of holomorphic functions. The removability of $\Gamma$ depends on the modulus of continuity; the results obtained are quite precise, as shown by examples based on careful estimation of Fourier coefficients. It is most surprising that the results are nearly the same for the holomorphic functions, and even for functions conformal off $\Gamma$.

Let $\Gamma$ be the graph of a continuous real function $y=y(x), 0 \leq x \leq 1$. Then $C^{r}(\Gamma)(r=1,2,3, \ldots)$ denotes the class of complex functions, continuous on $R^{2}$ and of class $C^{r}\left(R^{2} \backslash \Gamma\right)$, whose partial derivatives up to order $r$ admit continuous extensions to all of $R^{2}$. Again, $A^{r}(\Gamma)$ contains the elements of $C^{r}(\Gamma)$, holomorphic in $R^{2} \backslash \Gamma$. We say that $\Gamma$ is removable $C^{r}$, abbreviated $N_{r}$, if the functions in $C^{r}(\Gamma)$ are necessarily of class $C^{1}\left(R^{2}\right)$, and $N_{r}^{a}$ is defined with $A^{r}(\Gamma)$ in place of $C^{r}(\Gamma)$. (Remark 1, explaining the definition of $N_{r}$, is placed after Theorem 2.)

Our conclusions on class $N_{r}$ and $N_{r}^{a}$ can be summarized as follows: a close connection exists between the modulus of continuity of $y$ and removability properties of $\Gamma$, and this connection is about the same for $N_{r}$ and the (ostensibly larger) class $N_{r}^{a}$. We do not know how to prove that $N_{r}^{a} \neq N_{r}$; an explanation for this anomaly appears as Remark 2. In finding curves $\Gamma$, not of class $N_{r}^{a}$, we are led to find elements of $A^{r}(\Gamma)$ with even stronger properties, so that one obtains a larger class that might coincide with $N_{r}^{a}$.

The modulus of continuity of $y$ is

$$
\omega(h)=\omega(y ; h) \equiv \sup \left\{\left|y\left(x_{1}\right)-y\left(x_{2}\right)\right|,\left|x_{1}-x_{2}\right| \leq h\right\} .
$$

THEOREM 1. If $\lim \sup _{h \rightarrow 0} \omega(h) h^{-1 / r+1}<+\infty$, then $\Gamma$ is of class $N_{r}$.

THEOREM 2. Let $\psi(t)$ be a positive, increasing function on $0<t<1$ and $\lim \sup \psi(t) t^{-1 / r+1}=+\infty$; then there is a curve $\Gamma: y=y(x), 0 \leq x$ $\leq 1$, such that

$$
\lim \sup \omega(h) / \psi(h)=0
$$


and an element $\varphi$ of $A^{r}(\Gamma)$, which is not entire, defining a homeomorphism of $R^{2}$ onto itself, whose inverse is a contraction mapping of $R^{2}$.

For the method used, compare [2].

1. Proof of Theorem 1. Let $M$ be a square $|x|<c,|y|<c$ containing $\Gamma$ and $\varphi \in C^{r}(\Gamma)$. When $\left(x, y_{1}\right) \in M,\left(x, y_{2}\right) \in M$, then plainly $\mid \varphi\left(x, y_{1}\right)$ $-\varphi\left(x, y_{2}\right)|\leq c| y_{1}-y_{2} \mid$, for each fixed function $\varphi$ in $C^{r}(\Gamma) \subseteq C^{1}(\Gamma)$. Suppose next that $\left(x_{1}, y_{1}\right) \in M,\left(x_{2}, y_{2}\right) \in M$, and $y_{1}>y\left(x_{1}\right), y_{2}>$ $y\left(x_{2}\right)$. We join $\left(x_{1}, y_{1}\right)$ to $\left(x_{2}, y_{2}\right)$ by a path $\gamma$, entirely in $M \backslash \Gamma$; clearly the length $l$ of $\gamma$ can be made at most $\left|x_{1}-x_{2}\right|+\left|y_{1}-y_{2}\right|+$ $2 \omega\left(\left|x_{1}-x_{2}\right|\right)$. Let $p(x, y)$ be the Taylor polynomial, of order $r$, of $\varphi$ at $z_{1}$. We assert that $\varphi\left(x_{2}, y_{2}\right)-p\left(x_{2}, y_{2}\right)=o(1) \cdot l^{r}$, where $o(1)$ refers to small distances $\left|z_{1}-z_{2}\right|$. More exactly $\varphi(x, y)-p(x, y)=$ $o(1) \cdot l(x, y)^{r}$, where $l(x, y)$ is the distance between $\left(x_{1}, y_{1}\right)$ and $(x, y)$ along $\gamma$. This is true if $r=0$ (no derivatives!) and then follows by induction. Combining this with out estimate for $\varphi\left(x, y_{1}\right)-\varphi\left(x, y_{2}\right)$, we see that for $z_{1}, z_{2} \in M$

$$
\begin{aligned}
\left|\varphi\left(z_{1}\right)-\varphi\left(z_{2}\right)\right| & =O\left(\left|z_{1}-z_{2}\right|\right)+o(1) \omega\left(\left|z_{1}-z_{2}\right|\right)^{r} \\
& \equiv \Omega\left(\left|z_{1}-z_{2}\right|\right),
\end{aligned}
$$

say.

Let $g \in C^{1}\left(R^{2}\right), \iint g(x, y) d x d y=1, g \geq 0, g(z)=0$ when $|z|>1$, and then define

$$
\varphi_{h}(z)=h^{-2} \iint \varphi(x-y, y-v) g\left(h^{-1} u, h^{-1} v\right) d x d y .
$$

We shall show that $\nabla \varphi_{h}$ converges in $L^{1}(M)$ as $h \rightarrow 0+$ along a subsequence $h_{\nu}$, and this clearly proves that $\varphi \in C^{1}\left(R^{2}\right)$. On the part of $M$ defined by $d(z, \Gamma)>h, \nabla \varphi_{h}=O(1)$, and on the remaining part of $M$ a change of variables yields the estimate $\nabla \varphi_{h}=O\left(h^{-1}\right) \Omega(h)$.

Now $\lim \inf h^{-1} \Omega(h) \omega(h)=0$, so it will be enough to prove that $m\{z: d(z, \Gamma)<h\}=O(\omega(h))+O(h)$. To do so we observe that when $d(z, \Gamma)<h$ and $(k-1)<x<k h$, then $\left|y(x)-y\left(\left(k-\frac{1}{2}\right) h\right)\right| \leq h+$ $\omega(h)$, so the measure is $O\left(h^{-1}\right) \cdot O(h) \cdot O(h+\omega(h))$.

In the definition of $C^{r}(\Gamma)$, the continuity of the $r$ th order derivatives can be weakened to boundedness, provided liminf $\omega(h) h^{-1 / r+1}=0$. It is unclear whether both hypotheses can be retained in the weaker form, to conclude that $\nabla \varphi$ is locally in $L^{\infty}$.

2. Proof of Theorem 2. Because of the complications of the construction, we present an outline first. The operator $J$ is defined by

$$
(J f)(\zeta) \equiv \iint f(z)(z-\zeta)^{-1} d x d y
$$


When $f$ is smooth and integrable, then $J f$ is smooth, and $\bar{\partial}(J f)$ $\equiv \frac{1}{2}(\partial / \partial x+i \partial / \partial y)(J f)=-\pi f$ (a formula that will be useful later). The proof begins with a smooth function $f_{0} \geq 0$, vanishing off $0 \leq$ $x \leq 1 / 2, \quad 0 \leq y \leq 1 / 2$, and constructs $f_{1}, \ldots, f_{k}, \ldots$ so that $J\left(f_{0} \cdots f_{k}\right), \ldots, \partial^{r} J\left(f_{0} \cdots f_{k}\right) / \partial y^{r}$ converge uniformly as $k \rightarrow \infty$. The singular set of the limit $w$ will be the graph of a function defined over a set $E \subseteq[0,1]$, and linear interpolation will yield the graph $\Gamma$. Since $\partial^{r} w / \partial y^{r}$ is continuous on all of $R^{2}, w \in A^{r}(\Gamma)$ by the Cauchy-Riemann equations. Using the operator $\bar{\partial}$, we then find that $\varphi=+w-A z$ with a constant $A>0$, has the properties claimed.

Lemma 1. Let $g \in C^{1}\left(R^{2}\right), g=0$ when $x^{2}+y^{2} \geq 1$. Then

$$
\iint \exp 2 \pi i(u x+v y) g(x, y)(z-\zeta)^{-1} d x d y=O(1) \cdot(1+|u|+|v|)^{-1} \text {. }
$$

Proof. It will be convenient to abbreviate $e(t) \equiv \exp 2 \pi i t$. Clearly nothing is lost in assuming $v=0, u>0$. Moreover, only the case $|\zeta|<2$ is interesting and $\zeta=0$ is typical. Let $H(x, y)$ be a radial function, of class $C^{1}$ and vanishing for $x^{2}+y^{2}>1$, and let $H(0,0)=1$. Then

$$
\begin{aligned}
\iint e(u x) H(x, y) z^{-1} d x d y & =\int_{0}^{2 \pi} \int_{0}^{\infty} e(u r \cos \theta) H(r) e^{-i \theta} d r d \theta \\
& =\int_{0}^{2 \pi} \int_{0}^{\infty} e(u r \cos \theta) H(r) \cos \theta d r d \theta
\end{aligned}
$$

Now $\int_{0}^{t} e(u r \cos \theta) \cos \theta d r=O\left(|u|^{-1}\right)$ uniformly for $u>0, t>0$, so the integral is $O\left(|u|^{-1}\right)$, since $\int_{0}^{\infty}\left|H^{\prime}(r)\right| d r<\infty$.

Moreover, $[g(x, y)-g(0,0) H(x, y)](x+i y)^{-1}$ has a gradient in $L^{1}\left(R^{2}\right)$, whence

$$
\iint e(u x)[g(x, y)-g(0,0) H(x, y)](x+i y)^{-1} d x d y=O\left(|u|^{-1}\right) .
$$

$A$ sequence of functions. We choose and fix a function $a \in C^{\infty}(R)$, such that $a \geq 0, \int_{-1}^{1} a(t) d t=1$, and $a(t)=0$ for $|t| \geq 1$. We then define $A_{T}(x)$ (or $A(T ; x)$ for typographical reasons) for $T \geq 2$ as $T a(T x)$ for $|x| \leq 1 / 2$, and extend $A_{T}$ to be 1 -periodic on $R$. For the Fourier expansion

$$
A_{T}(x)=1+\sum^{\prime} a_{n}^{T} e(n x)
$$

we have

$$
\left|a_{n}^{T}\right| \leq 1, \quad\left|a_{n}^{T}\right| \leq c_{p} T^{P}|n|^{-p}
$$

for $p=1,2,3, \ldots$ 
Let now $G(x, y)$ be a function of class $C^{\infty}$ and compact support, let $S>2$ and $T>2$ be parameters, and

$$
F(S, T ; \zeta)=\iint G(x, y) A(T ; y-S x)(z-\zeta)^{-1} d x d y
$$

LEMMA 2. $F(S, T)$ and $\partial^{p} F(S, T) / \partial \eta^{p}=O\left(T^{r} S^{-1}\right), 1 \leq p \leq r$.

Proof. Writing the Fourier expansion

$$
A(T ; y-S x)-1=\Sigma^{\prime} a_{n}^{T} e(n y-n S x),
$$

we substitute this in $F(S, T ; \zeta)$. The partial derivatives $\partial / \partial \eta, \partial^{2} / \partial \eta^{2}, \ldots$ can be effected by applying $\partial / \partial y, \partial^{2} / \partial y^{2}, \ldots$ to the cofactor of $(z-\zeta)^{-1}$. After using Leibniz' rule in these derivatives, and applying Lemma 1 to the resulting integrals we get, for $\partial^{r} / \partial y^{r}$ (taking $\left.p=r+1\right) c(G) \sum_{1}^{\infty} n^{r}$. $\min \left(1, n^{-r-1} T^{r+1}\right) n^{-1} S^{-1} \leq c(G) T^{r} S^{-1}$.

To prove Theorem 2 , we choose a smooth function $G_{0} \geq 0$, vanishing off $0<x<1,0<y<1 / 2$, and choose $S_{k}>T_{k}>4+k$ so that the sequences defined by

$$
w_{k}(\zeta) \equiv \iint G_{0}(x, y) \prod_{1}^{j} A\left(T_{j}, y-S_{j} x\right)(z-\zeta)^{-1} d x d y
$$

and $\partial^{p} w_{k} / \partial \eta^{p}(1 \leq p \leq r)$ converge uniformly; of course we require that $w=\lim w_{k} \not \equiv 0$. At each step, this can be accomplished by choosing $S_{k}=c_{k-1} T_{k}^{r}$, with a constant $c_{k-1}$ depending only on $G_{0}$ and $S_{1}, T_{1}, \ldots, S_{k-1}, T_{k-1}$. Furthermore, since $\lim \sup \psi(t) t^{-1 / r+1}=+\infty$, we can choose $T_{k}$ so that $T_{k}^{-1}<k^{-1} \psi\left(c_{k-1}^{-1} T_{k}^{-r-1}\right)$.

Clearly $w$ is holomorphic off the set $0 \leq x \leq 1,0 \leq y \leq \frac{1}{2}\left|y-S_{k} x\right|$ $\leq T_{k}^{-1}$ (modulo 1). On this set $y$ is a single-valued function of $x, y=y(x)$; let $E$ be the closed set in $[0,1]$ over which $y$ is defined, and let $\bar{y}$ be obtained from $y$ by linear interpolation on the intervals contiguous to $E$ in its convex hull.

We first calculate the modulus of continuity $\omega(y ; h)$ for certain values of $h>0$. Let $\left(x_{1}, y_{1}\right),\left(x_{2}, y_{2}\right)$ belong to $E$, and $\left|x_{1}-x_{2}\right| \leq S_{k}^{-1} / 4$. We write, for $j=1,2$

$$
y_{j}=S_{k} x_{j}+\theta_{j} T_{k}^{-1}+N_{j} \quad\left(N_{j} \in Z,\left|\theta_{j}\right| \leq 1\right) .
$$

Since $T_{k}^{-1}<1 / 4$ and $S_{k}\left|x_{1}-x_{2}\right|<1 / 4$, we have $\left|y_{1}-y_{2}\right| \leq 2 T_{k}^{-1}+$ $S_{k}\left|x_{1}-x_{2}\right|<1$ (modulo 1). Since $\left|y_{1}-y_{2}\right|<1 / 2$, then $N_{1}=N_{2}$ and $\left|y_{1}-y_{2}\right| \leq 2 T_{k}^{-1}+S_{k}\left|x_{1}-x_{2}\right|$. It follows from this that $\left|y_{1}-y_{2}\right| \leq$ $2 T_{k}^{-1}+2 S_{k}\left|x_{1}-x_{2}\right|$ for all values of $x_{1}, x_{2}$ in $E$, that is $\omega(y, h) \leq$ $2 T_{k}^{-1}+2 S_{k} h$. From this it follows that $\omega(\bar{y}, h) \leq 4 T_{k}^{-1}+4 S_{k} h$, and in 
particular $\omega\left(\bar{y}, S_{k}^{-1} T_{k}^{-1}\right) \leq 8 T_{k}^{-1}$. We recall that $S_{k}=c_{k-1} T_{k}^{r}$, so that

$$
\omega\left(\bar{y}, S_{k}^{-1} T_{k}^{-1}\right)=\omega\left(\bar{y}, c_{k-1}^{-1} T_{k}^{-r-1}\right) \leq 8 T_{k}^{-1}<3 k^{-1} \psi\left(c_{k-1}^{-1} T_{k}^{-r-1}\right),
$$

or $\liminf \omega(\bar{y}, h) / \psi(h)=0$.

We shall now select a constant $A>0$ so that each mapping $w_{k}-A z$ $=\varphi_{k}$ has positive determinant and $\left|d \varphi_{k}\right| \geq|d z|$. The determinant is $\left|\partial \varphi_{k}\right|^{2}$ - $\left|\bar{\partial} \varphi_{k}\right|^{2}$, and the minimum of $\left|d \varphi_{k}\right| /|d z|$ is ||$\partial \varphi_{k}|-| \bar{\partial} \varphi_{k}||$. Thus we need to choose $A$ so that $\left|\partial w_{k}-A\right| \geq 1+\left|\bar{\partial} w_{k}\right|$, using the inequalities $\left|\partial w_{k} / \partial y\right|$ $\leq c_{1}, \bar{\partial} w_{k} \leq 0$. This can be done with $A=1+2 c_{1}$. It is worthwhile to observe that $\varphi(\Gamma)$ must have positive measure, for otherwise $\varphi^{-1}$ is entire and $w \equiv 0$. This completes the proof of Theorem 2 .

REMARK 1. The function $w$ found in Theorem 2 can be represented

$$
w(\zeta)=\iint(z-\zeta)^{-1} \mu(d z)
$$

with a certain non-negative $\mu$ on $\Gamma$. Choosing $\Gamma$ of class $N_{r+1}^{a}$, but not $N_{r}^{a}$ (this will be true if $\psi(t)=t^{\sigma}, \sigma=2(2 r+3)^{-1}$ ) we define

$$
\Phi(\zeta)=\iint \log |z-\zeta| \mu(d \zeta), \quad \zeta \notin \Gamma .
$$

Then $\partial \Phi=-1 / 2 w$ off $G$, and $\Phi$ has a gradient locally in $L^{1}$. Hence $\partial \Phi=-w / 2$ in the classical sense, and since $\Phi$ is real, $\Phi \in C^{r+1}(\Gamma)$. Now $\Phi \in C^{1}\left(R^{2}\right)$ is clear, but $\Phi \notin C^{2}\left(R^{2}\right)$, because $\nabla^{2} \Phi=2 \pi \mu$, a singular measure.

REMARK 2. It seems very difficult to prove that $N_{1}^{a} \neq N_{1}$. To explain this, we summarize a sufficient condition for a Cantor set $S$ to be of class $N_{1}^{a}$, from [1]. To each $\varepsilon>0$, there exist Jordan curves $\gamma_{1}, \ldots, \gamma_{m}$ in $R^{2} \backslash S$, of length $<\varepsilon$, surrounding $S$ in the homology sense, and $\sum l\left(\gamma_{j}\right)^{2}$ $\leq C$. Unfortunately, this condition also forces $S \in N_{1}$. Our condition can be adapted to curves crossing $\Gamma$ only in horizontal segments, and again forces $\Gamma \in N_{1}$.

\section{REFERENCES}

[1] R. Kaufman, Two problems on removable sets for analytic functions, Arkiv för Matematik, 20 (1982), 14-22.

[2] , Fourier-Stieltjes coefficients and continuation of functions, Annales Acad. Sci. Fennicae, 9 (1984), 27-31.

Received June 29, 1985. This research was supported in part by the National Science Foundation and the Center for Advanced Study of the University of Illinois. 



\title{
PACIFIC JOURNAL OF MATHEMATICS \\ EDITORS
}

\author{
V. S. VARADARAJAN \\ (Managing Editor) \\ University of California \\ Los Angeles, CA 90024 \\ HERBERT CLEMENS \\ University of Utah \\ Salt Lake City, UT 84112 \\ R. FINN \\ Stanford University \\ Stanford, CA 94305
}

\author{
HERMANN FLASCHKA \\ University of Arizona \\ Tucson, AZ 85721
}

RAMESh A. GANGOLLI

University of Washington Seattle, WA 98195

VAUGHAN F. R. JONES

University of California

Berkeley, CA 94720

ROBION KIRBY

University of California

Berkeley, CA 94720
C. C. MOORE

University of California

Berkeley, CA 94720

H. SAMELSON

Stanford University

Stanford, CA 94305

HAROLD STARK

University of California, San Diego

La Jolla, CA 92093

\section{ASSOCIATE EDITORS}

\author{
R. ARENS \\ E. F. BECKENBACH \\ B. H. NeUmanN \\ F. WOLF \\ K. YOSHIDA \\ (1906-1982)

\section{SUPPORTING INSTITUTIONS} \\ UNIVERSITY OF ARIZONA \\ UNIVERSITY OF BRITISH COLUMBIA \\ CALIFORNIA INSTITUTE OF TECHNOLOGY \\ UNIVERSITY OF CALIFORNIA \\ MONTANA STATE UNIVERSITY \\ UNIVERSITY OF NEVADA, RENO \\ NEW MEXICO STATE UNIVERSITY \\ OREGON STATE UNIVERSITY \\ UNIVERSITY OF OREGON \\ UNIVERSITY OF SOUTHERN CALIFORNIA \\ STANFORD UNIVERSITY \\ UNIVERSITY OF HAWAII \\ UNIVERSITY OF TOKYO \\ UNIVERSITY OF UTAH \\ WASHINGTON STATE UNIVERSITY \\ UNIVERSITY OF WASHINGTON
}

The Supporting Institutions listed above contribute to the cost of publication of this Journal, but they are not owners or publishers and have no responsibility for its content or policies.

Mathematical papers intended for publication in the Pacific Journal of Mathematics should be in typed form or offset-reproduced (not dittoed), double spaced with large margins. Please do not use built up fractions in the text of the manuscript. However, you may use them in the displayed equations. Underline Greek letters in red, German in green, and script in blue. The first paragraph must be capable of being used separately as a synopsis of the entire paper. In particular it should contain no bibliographic references. Please propose a heading for the odd numbered pages of less than 35 characters. Manuscripts, in triplicate, may be sent to any one of the editors. Please classify according to the scheme of Math. Reviews, Index to Vol. 39. Supply name and address of author to whom proofs should be sent. All other communications should be addressed to the managing editor, or Elaine Barth, University of California, Los Angeles, California 90024.

There are page-charges associated with articles appearing in the Pacific Journal of Mathematics. These charges are expected to be paid by the author's University, Government Agency or Company. If the author or authors do not have access to such Institutional support these charges are waived. Single authors will receive 50 free reprints; joint authors will receive a total of 100 free reprints. Additional copies may be obtained at cost in multiples of 50 .

The Pacific Journal of Mathematics is issued monthly as of January 1966. Regular subscription rate: $\$ 190.00$ a year (5 Vols., 10 issues). Special rate: $\$ 95.00$ a year to individual members of supporting institutions.

Subscriptions, orders for numbers issued in the last three calendar years, and changes of address should be sent to Pacific Journal of Mathematics, P.O. Box 969, Carmel Valley, CA 93924, U.S.A. Old back numbers obtainable from Kraus Periodicals Co., Route 100, Millwood, NY 10546.

The Pacific Journal of Mathematics at P.O. Box 969, Carmel Valley, CA 93924 (ISSN 0030-8730) publish'es 5 volumes per year. Application to mail at Second-class postage rates is pending at Carmel Valley, California, and additional mailing offices. Postmaster: send address changes to Pacific Journal of Mathematics, P.O. Box 969, Carmel Valley, CA 93924.

PUBLISHED BY PACIFIC JOURNAL OF MATHEMATICS, A NON-PROFIT CORPORATION

Copyright (C) 1986 by Pacific Journal of Mathematics 


\section{Pacific Journal of Mathematics}

\section{Vol. 125, No. $2 \quad$ October, 1986}

Dale Edward Alspach, On $\mathscr{L}_{p, \lambda}$ spaces for small $\lambda \ldots \ldots \ldots \ldots \ldots \ldots 257$

Jong Sook Bae and Sangsuk Yie, Range of Gateaux differentiable operators

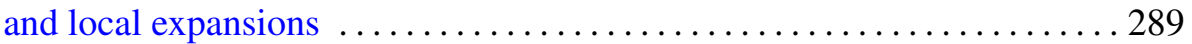

Hubert Berens and Lothar Hetzelt, On accretive operators on $l_{n}^{\infty} \ldots \ldots 301$

Marie-Françoise Bidaut-Véron, Global existence and uniqueness results for singular solutions of the capillarity equation ................. 317

Donald M. Davis and Mark Mahowald, Classification of the stable homotopy types of stunted real projective spaces ................. 335

Aad Dijksma, Heinz K. Langer and Hendrik S. V. de Snoo, Unitary

colligations in $\Pi_{\kappa}$-spaces, characteristic functions and Štraus extensions

Michel Enock and Jean-Marie Schwartz, Algèbres de Kac

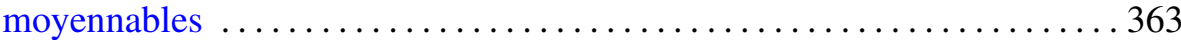

Seppo Granlund, Peter Lindqvist and Olli Martio, Note on the

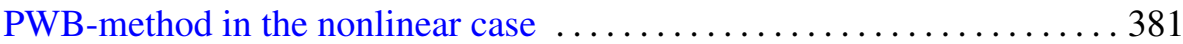

Palle E. T. Jorgensen, Analytic continuation of local representations of Lie

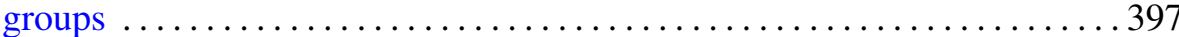

Robert P. Kaufman, Plane curves and removable sets ................409

José M. Montesinos and Wilbur Carrington Whitten, Constructions of two-fold branched covering spaces $\ldots \ldots \ldots \ldots \ldots$.

Benedict Seifert, Highly transitive group actions on trees and normalizing Tits systems

Charles Stuart Stanton, Counting functions and majorization for Jensen

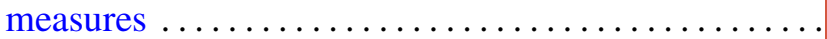

Luen-Fai Tam, On existence criteria for capillary free surfaces without gravity

Zhuocheng Yang, Exposed points of left invariant means 